\title{
BMJ Open Hypertension prevalence, associated factors, treatment and control in rural Cameroon: a cross-sectional study
}

\author{
Larissa Pone Simo, ${ }^{1,2}$ Valirie Ndip Agbor (1) , ${ }^{3}$ Jean Jacques N Noubiap, ${ }^{4}$ \\ Orlin Pagnol Nana, ${ }^{1}$ Pride Swiri-Muya Nkosu, ${ }^{1}$ Arnold Forlemu Asaah Anouboweh, ${ }^{1}$ \\ Jude Nfor Ndi, ${ }^{1}$ Jacques Nguend Mbock, ${ }^{1}$ Noel Fils Bakari, ${ }^{1}$ \\ Harold Giovani Guifo Tambou, ${ }^{1}$ Dora Mbanya ${ }^{1}$
}

To cite: Simo LP, Agbor VN, Noubiap JJN, et al. Hypertension prevalence, associated factors, treatment and control in rural Cameroon: a cross-sectional study. BMJ Open 2020;10:e040981. doi:10.1136/ bmjopen-2020-040981

- Prepublication history for this paper is available online. To view these files, please visit the journal online (http://dx.doi org/10.1136/bmjopen-2020040981).

Received 28 May 2020 Revised 03 July 2020 Accepted 16 July 2020

Check for updates

(C) Author(s) (or their employer(s)) 2020. Re-use permitted under CC BY-NC. No commercial re-use. See rights and permissions. Published by BMJ.

${ }^{1}$ Department of Clinical Medicine, Faculty of Health

Sciences, University of

Bamenda, Bamenda, Cameroon

${ }^{2}$ Dzeng Sub-divisional Hospital,

Dzeng, Centre Region,

Cameroon

${ }^{3}$ Nuffield Department of

Population Health, University of Oxford, Oxford, UK

${ }^{4}$ Centre for Heart Rhythm Disorders, University of Adelaide and Royal Adelaide Hospital,

Adelaide, South Australia, Australia

Correspondence to Dr Valirie Ndip Agbor; nvagbor@gmail.com

\section{ABSTRACT}

Introduction Sub-Saharan Africa is experiencing a surge in the burden of hypertension, and rural communities are increasingly affected by the epidemic.

Objectives We aimed to determine the prevalence of and factors associated with hypertension in rural communities of the Baham Health District (BHD), Cameroon. In addition, we sought to assess awareness, treatment and control rates of hypertension among community members. Design A community-based cross-sectional study. Setting Participants from five health areas in the BHD were recruited from August to October 2018.

Participants Consenting participants aged 18 years and above were included.

Results We included 526 participants in this study. The median age of the participants was 53.0 (IQR=35-65) years and $67.1 \%$ were female. The crude prevalence of hypertension was $40.9 \%(95 \% \mathrm{Cl}=36.7-45.1)$ with no gender disparity. The age-standardised prevalence of hypertension was $23.9 \%(95 \% \mathrm{Cl}=20.3-27.5)$. Five-year increase in age (adjusted $O R(A O R)=1.34$; $95 \% \mathrm{Cl}=1.23-1.44)$, family history of hypertension $(\mathrm{AOR}=2.22 ; 95 \% \mathrm{Cl}=1.37-3.60)$ and obesity $(\mathrm{AOR}=2.57$; $95 \% \mathrm{Cl}=1.40-4.69$ ) were associated with higher odds of hypertension after controlling for confounding. The rates of awareness, treatment and control of hypertension were $37.2 \%(95 \% \mathrm{Cl}=31.0-43.9), 20.9 \%(95 \% \mathrm{Cl}=16.0-26.9)$ and $22.2 \%(95 \% \mathrm{Cl}=12.2-37.0)$, respectively.

Conclusion The high prevalence of hypertension in these rural communities is associated with contrastingly low awareness, treatment and control rates. Age, family history of hypertension and obesity are the major drivers of hypertension in this community. Veracious policies are needed to improve awareness, prevention, diagnosis, treatment and control of hypertension in these rural communities.

\section{BACKGROUND}

Hypertension is a major modifiable risk factor for cardiovascular diseases globally, ${ }^{12}$ which is associated with increased costs on health systems, high morbidity and premature mortality. Globally, it is estimated that one billion adults live with hypertension; a figure which is projected to hit 1.5 billion by
Strengths and limitations of this study

Due to the non-probabilistic sampling method used, and the high proportion of elderly people in our study, this report may overestimate the prevalence of hypertension in these rural communities.

- Random error in and non-differential classification of hypertension in our study due to the use of a onetime blood pressure measure is likely to have reduced the power of our regression analyses.

- There is potential for residual confounding from measured and unmeasured confounders.

- Our study did not explore the determinants of controlled hypertension, including medication adherence.

- This study investigated the contribution of nontraditional factors such as wood smoke and consumption of fruits and vegetables to the prevalence of hypertension in these rural communities.

the year 2025. ${ }^{23}$ Furthermore, hypertensionrelated complications are responsible for over $50 \%$ of the 17.4 million annual deaths caused by cardiovascular diseases globally. ${ }^{2}$ At least $45 \%$ of deaths due to heart disease and $51 \%$ of deaths due to stroke are related to hypertension. ${ }^{2}$

Cardiovascular diseases are the second most common cause of premature disability and death in sub-Saharan Africa (SSA). ${ }^{4-6}$ A large proportion of the burden of heart disease, kidney failure, strokes and premature deaths in this region are caused by hypertension. ${ }^{7-10}$ The prevalence of hypertension in SSA is estimated at about $30 \%$ with disproportionately low awareness, treatment and control rates. ${ }^{7}$ About $29.7 \%$ of the general Cameroonian population are affected by hypertension. ${ }^{8} \mathrm{~A}$ significant number of cases of hypertension still remain undiagnosed and untreated, and even patients who receive treatment rarely achieve a controlled blood pressure. ${ }^{9-12}$ 
With the increasing prevalence of hypertension globally, including the rural areas, a continuous evaluation of the burden of hypertension in these rural communities is needed to plan prevention and control strategies. A limited number of community-based studies have assessed the epidemiology of hypertension in rural areas in Cameroon with significant disparities across regions. Cognizant to this, we sought to assess the prevalence and factors associated with hypertension among adults in selected health areas in a rural health district in the West Region of Cameroon. In addition, we evaluated the rates of awareness, treatment and control of hypertension in the same population.

\section{METHODS}

\section{Study design, setting and duration}

This was a community-based cross-sectional study conducted between August and October 2018 in the Baham Health District (BHD), as part of the University of Bamenda Medical Students Association (UBaMSA) annual community health campaign. The study was conducted in five of the nine health areas of the BHD, including the Hiala Cheffou, Bapa, Baham and Ngouogoua health areas. Baham is a rural community located in the West Region of Cameroon. The BHD had an estimated population of 51500 in $2001^{13}$ whose major activity is farming. It is made up of nine health areas with a district hospital.

\section{Study population and sampling}

The five health areas in which our study was conducted were selected based on ease of accessibility. Consenting participants aged 18 years and above were consecutively recruited for the study. Participants with documented or reported a diagnosis of chronic kidney disease, those who had taken cardiostimulants, such as alcohol, 'kola nut' (a caffeine-containing fruit of the Kola tree; a genus of trees that are native to the tropical rainforests of Africa) and caffeine at least $30 \mathrm{~min}$ prior to the study, and pregnant women were excluded from the study.

The sample size was estimated using the following formula:

$$
\mathrm{n}=\frac{\mathrm{Z}^{2} \mathrm{P}(1-\mathrm{P})}{\mathrm{d}^{2}}
$$

where $n$ is the sample size (number of adult participants), $\mathrm{P}$ is the expected prevalence of hypertension in an adult population $(\mathrm{P}=0.378),{ }^{12}$ and $\mathrm{d}$ is the precision (if $5 \%, d=0.05)$. $Z$ statistics $(Z)$ : for the level of confidence of $95 \%$, which is conventional, $\mathrm{Z}$ value is 1.96 for a $95 \%$ CI. A minimum of 361 adult participants was required for this study.

\section{Study procedure and data collection}

One month prior to the UBaMSA health campaign, members of the community were informed by mass communication (through the local radio stations), and interpersonal communication on the dates retained for activities of the campaign. The data collection process was guided by the WHO step wise approach to surveillance. Data were collected by trained medical students and medical doctors. Information on the participants' demographics (such as age, sex and education), lifestyle (fruits and vegetable consumption, smoking status and physical activity) and medical history (family history of hypertension). In cases where participants did not understand English or French, a translator was used.

Blood pressure was measured using a reference protocol in which participants were seated, and measurements were taken after at least $10 \mathrm{~min}$ of rest. This was done using the auscultatory method with a calibrated analogue sphygmomanometer placed at least $0.5 \mathrm{~cm}$ above the elbow joint, covering at least $80 \%$ of the arm and a stethoscope was used to detect the korotkoff sounds. The analysis was done for the average of two measures performed at least $5 \mathrm{~min}$ apart.

Height was measured using a calibrated stadiometer to the nearest $0.1 \mathrm{~cm}$. Weight was measured to the nearest $0.5 \mathrm{~kg}$ with the use of a scale, and the participants mounted the scale only wearing light clothing. Abdominal circumference was measured to the nearest $0.5 \mathrm{~cm}$ with a measuring tape placed all around the bare abdomen at the level of the umbilicus.

\section{Definitions}

1. Respondents were considered as hypertensive if they had an average SBP of $140 \mathrm{~mm} \mathrm{Hg}$ or higher, or DBP of $90 \mathrm{~mm} \mathrm{Hg}$ or greater, or reported current use of antihypertensive medication. ${ }^{14}$

2. Hypertension awareness rate was defined as the proportion of individuals who responded 'yes' to being diagnosed with hypertension by a healthcare professional and/or 'yes' to taking medication for hypertension.

3. The rate of hypertension treatment included the proportion of participants who were diagnosed with hypertension and reported being on treatment for hypertension.

4. Hypertension control was defined as the proportion of individuals on either pharmacotherapy or implementing lifestyle modification methods or both for hypertension and who had an average $\mathrm{SBP}<140 \mathrm{~mm}$ $\mathrm{Hg}$ and $\mathrm{DBP}<90 \mathrm{~mm} \mathrm{Hg}$.

5. Occupational level was classified into 'low' (no technical know-how or expert training required, eg, manual workers), 'medium' (requiring a degree of technical know-how but no expert training, like salesmen and bike and taxi drivers) and 'high' (major professionals requiring advanced training, such as teachers, health personnel and accountants).

6. We defined an ex-smoker as someone who has smoked at least 100 cigarettes in their lifetime but had stopped smoking at least 28 days before the interview. A smoker was defined as someone who has smoked at least 100 cigarettes in their lifetime and is still regular smokers at the time of the interview. Those who had 
never smoked or smoked less 100 cigarettes in their lifetime were classified as non-smokers.

7. Alcohol units per week $=$ (number of bottles of beer consumed per week) $\times 5 \% \times 650 \mathrm{~mL} / 1000 .^{15}$ The routine beer bottle in Cameroon has a volume of $650 \mathrm{~mL}$, and the beer has an alcohol concentration of $5 \%$.

8. The intensity of physical activity was classified as 'moderate' (eg, brisk walking, moderate farm work like weeding and harvesting, haunting, lifting masses $<20 \mathrm{~kg}$, housework and domestic chores and general building tasks, such as roofing and painting) and 'vigorous' (running, briskly ascending and descending hills, intense farm work such as manual tilling of the soil, digging ditches and carrying masses $>20 \mathrm{~kg}$ ). ${ }^{16}$ Sedentary lifestyles at work and home were classified as 'no physical activity'.

9. The body mass index (BMI) was calculated as the ratio of the weight in kilograms and the square of the height in metres. BMI-based body habitus (in $\mathrm{kg}$ / $\left.\mathrm{m}^{2}\right)$ was classified as underweight $(\mathrm{BMI}<18.5)$, normal weight (BMI $=18.5-24.9)$, overweight $(\mathrm{BMI}=25.0$ 29.9) and obese (BMI $\geq 30) .{ }^{17}$

10. Abdominal obesity was defined as an abdominal circumference $\geq 102 \mathrm{~cm}$ in men or $\geq 88 \mathrm{~cm}$ in women. ${ }^{18}$

\section{Data analysis}

Data were analysed with Stata V.16 (StataCorp 2019, StataCorp LLC, College Station, Texas, USA). Qualitative variables were reported using counts and percentages. Quantitative variables were summarised as means and medians with their corresponding SD and IQR, respectively. We computed direct age-standardised prevalence of hypertension using the 2011 population structure of Cameroon. ${ }^{19}$ For univariate analyses, the Pearson $\chi^{2}$ test was used to compare categorical variables while the Wilcoxon rank-sum test was used to compare medians across independent groups. The Pearson correlation test was used to assess the association between two normally distributed quantitative variables. Independent factors associated with hypertension were determined using unconditional maximum likelihood multivariable logistic regression models. Variables with a p value $<0.1$ on univariate analysis qualified for inclusion in the multivariable model. We sequentially adjusted for demographic factors (such as age, gender, occupation and education), lifestyle factors (smoking status, alcohol consumption, fruit consumption and physical activity) and clinical characteristics (family history of hypertension and BMI). The maximum likelihood ratio test was used to evaluate model fit and select variables for the final multivariable model. Gender, alcohol consumption and smoking status were retained in the final model as they have been reported as factors associated with hypertension in the literature. Body mass index was retained in the final model over abdominal obesity to facilitate comparison of our findings with previously published studies and to prevent multicollinearity. Ordinal variables were assessed for linear trend using the $\chi^{2}$ test for linear trend. The $\chi^{2}$ test for heterogeneity was used to evaluate departures from linearity. Measures of association are reported as OR with corresponding 95\% CI. Missing data were handled using simple mean, median or mode imputation where appropriate. Two-tailed $\mathrm{p}$ values $<0.05$ were considered statistically significant.

\section{Patient and public involvement}

Patients and/or the public were not directly involved in this study.

\section{RESULTS}

In total, 526 participants with a median age of 53.0 $(\mathrm{IQR}=35-65)$ years were included in this study. The ages of the participants ranged from 18 to 99 years. About $67 \%$ of the participants were females and $76.6 \%$ were married, table 1 . A little over half of the participants were Catholic Christians and about three-quarters of them had at least a primary education. The average BMI was $27.2(\mathrm{SD}=5.2)$, and about $44 \%$ of the participants had android obesity.

\section{Prevalence of hypertension}

Of the 526 participants, 215 were classified as hypertensive, giving an overall crude prevalence of $40.9 \%$ (95\% $\mathrm{CI}=36.7-45.1)$. Figure 1 shows the gender-specific prevalence of hypertension (with their 95\% CI) across different age groups. There was a linear increase in the prevalence of hypertension among older participants, with no gender disparity. The overall age-standardised prevalence of hypertension was $23.9 \%(95 \% \mathrm{CI}=20.3-27.5)$.

\section{Factors associated with hypertension}

On univariate analysis, participants with hypertension were significantly older (median age in years $=64.0$ years vs 42.0 years) and consumed fruits less regularly (median daily fruit consumption per week $=2.0$ vs 4.0 ) compared with those without hypertension, table 2. There was strong evidence against the null hypothesis of no difference in marital status, occupation, level of education, family history of hypertension and intensity of physical activity between participants with and without hypertension. There was weak evidence against the null hypothesis of no difference in exposure to wood smoke between participants with and without hypertension. There was a moderate positive correlation between BMI and abdominal circumference $(\mathrm{r}=0.60, \mathrm{p}<0.001)$.

Figure 2 displays the final multivariable logistic regression model (without abdominal obesity). There was strong evidence of a $34 \%$ increase in the odds of hypertension for every 5-year increase in age (adjusted OR $(\mathrm{AOR})=1.34 ; 95 \% \mathrm{CI}=1.23-1.44 ; \mathrm{p}<0.001)$. Family history of hypertension was associated with 2.22 times higher odds of hypertension (AOR=2.22; 95\% CI=1.37-3.60; $\mathrm{p}<0.001)$. Obesity was associated with 2.57 times higher odds of hypertension (AOR=2.57; 95\% CI $=1.40-4.69$; $\left.\mathrm{p}_{\text {trend }}<0.001\right)$. 
Table 1 Characteristics of the study population, Baham Health District, 2018

\begin{tabular}{|c|c|c|c|}
\hline Participants' characteristics & $\begin{array}{l}\text { Female } \\
(n=353)\end{array}$ & $\begin{array}{l}\text { Male } \\
(n=173)\end{array}$ & $\begin{array}{l}\text { Total } \\
(n=526)\end{array}$ \\
\hline Age (in years) ${ }^{*}$ & $54.0(36.0-65.0)$ & $50.0(33.0-66.0)$ & $53.0(35.0-65.0)$ \\
\hline \multicolumn{4}{|l|}{ Age groups (in years) } \\
\hline $18-39$ & $98(27.8 \%)$ & $59(34.1 \%)$ & $157(29.8 \%)$ \\
\hline $40-59$ & $120(34.0 \%)$ & $50(28.9 \%)$ & $170(32.3 \%)$ \\
\hline 60 and over & $135(38.2 \%)$ & $64(37.0 \%)$ & $199(37.8 \%)$ \\
\hline Marital status (Married) & $282(79.9 \%)$ & $121(69.9 \%)$ & $403(76.6 \%)$ \\
\hline \multicolumn{4}{|l|}{ Occupation } \\
\hline High & $11(3.1 \%)$ & $11(6.4 \%)$ & $22(4.2 \%)$ \\
\hline Medium & $40(11.3 \%)$ & $73(42.2 \%)$ & $113(21.5 \%)$ \\
\hline Low & $302(85.6 \%)$ & $89(51.4 \%)$ & $391(74.3 \%)$ \\
\hline \multicolumn{4}{|l|}{ Religion } \\
\hline Baptist & $9(2.5 \%)$ & $4(2.3 \%)$ & $13(2.5 \%)$ \\
\hline Catholic & $190(53.8 \%)$ & $85(49.1 \%)$ & $275(52.3 \%)$ \\
\hline Muslim & $4(1.1 \%)$ & $10(5.8 \%)$ & $14(2.7 \%)$ \\
\hline Others & $76(21.5 \%)$ & $43(24.9 \%)$ & $119(22.6 \%)$ \\
\hline Pegan & $5(1.4 \%)$ & $14(8.1 \%)$ & $19(3.6 \%)$ \\
\hline Presbyterian & $69(19.5 \%)$ & $17(9.8 \%)$ & $86(16.3 \%)$ \\
\hline \multicolumn{4}{|l|}{ Level of education } \\
\hline No formal education & $100(28.3 \%)$ & $31(17.9 \%)$ & $131(24.9 \%)$ \\
\hline Primary & $114(32.3 \%)$ & $41(23.7 \%)$ & $155(29.5 \%)$ \\
\hline Secondary & $109(30.9 \%)$ & $74(42.8 \%)$ & $183(34.8 \%)$ \\
\hline Tertiary & $30(8.5 \%)$ & $27(15.6 \%)$ & $57(10.8 \%)$ \\
\hline Family history of hypertension (Yes) & $110(31.2 \%)$ & $31(17.9 \%)$ & $141(26.8 \%)$ \\
\hline \multicolumn{4}{|l|}{ Smoking status } \\
\hline Non-smoker & $334(94.6 \%)$ & $101(58.4 \%)$ & $435(82.7 \%)$ \\
\hline Ex-smoker & $12(3.4 \%)$ & $37(21.4 \%)$ & 49 (9.3\%) \\
\hline Current smoker & $7(2.0 \%)$ & $35(20.2 \%)$ & $42(8.0 \%)$ \\
\hline \multicolumn{4}{|l|}{ Alcohol units per week } \\
\hline Non-drinker & $122(34.6 \%)$ & $41(23.7 \%)$ & $163(31.0 \%)$ \\
\hline$(0.012-6.49]$ & $164(46.5 \%)$ & $41(23.7 \%)$ & 205 (39.0\%) \\
\hline$(6.492-117]$ & $67(19.0 \%)$ & $91(52.6 \%)$ & $158(30.0 \%)$ \\
\hline Body mass index (in $\left.\mathrm{kg} / \mathrm{m}^{2}\right) \dagger$ & $28.1(5.4)$ & $25.5(4.4)$ & $27.2(5.2)$ \\
\hline \multicolumn{4}{|l|}{ Body mass index categories } \\
\hline Normal & $100(28.3 \%)$ & $89(51.4 \%)$ & $189(35.9 \%)$ \\
\hline Overweight & $157(44.5 \%)$ & $63(36.4 \%)$ & $220(41.8 \%)$ \\
\hline Obese & $96(27.2 \%)$ & $21(12.1 \%)$ & $117(22.2 \%)$ \\
\hline Abdominal obesity (Yes) & $215(60.9 \%)$ & $18(10.4 \%)$ & $233(44.3 \%)$ \\
\hline Systolic blood pressure (in mm Hg) $†$ & $134.5(25.9)$ & $133.2(21.3)$ & $134.1(24.5)$ \\
\hline Diastolic blood pressure (in $\mathrm{mm} \mathrm{Hg}$ ) $†$ & $83.0(14.8)$ & $83.1(14.0)$ & $83.0(14.5)$ \\
\hline
\end{tabular}

*Summarised as median and IQR. †Data summarised as mean (SD). $\mathrm{n}$, frequency 


\section{Awareness, treatment and control of hypertension}

Table 3 depicts the percentage of hypertension awareness, treatment and control among our study participants. Of the 215 participants diagnosed with hypertension, $37.2 \%$ (95\% CI $=31.0-43.9)$ were aware of their hypertensive status, while $20.9 \%$ (95\% CI $=16.0-26.9)$ reported being on treatment for hypertension. Of the 45 participants who were on treatment for hypertension, $22.2 \%(95 \%$ CI=12.2-37.0) had a controlled BP.

\section{DISCUSSION}

We report a prevalence of hypertension of $40.9 \%$ (agestandardised prevalence $=23.9 \%$ ) with associated low awareness, treatment and control rates in the BHD. Older age, family history of hypertension and obesity were drivers of hypertension in this population.

\section{Prevalence of hypertension and associated factors}

The crude prevalence of hypertension in our study was higher than the crude prevalence of $33.9 \%$ and $31.1 \%$ in rural areas of the Far North Region ${ }^{12}$ and South West Region of Cameroon, ${ }^{20}$ respectively. This higher prevalence of hypertension in our study can be attributed to the older age of our study population compared with those of previous studies. Indeed, the median age of our study participants was 53 years compared with a mean age of 39 years reported by Lemogoum et al. ${ }^{12}$ In addition, over $65 \%$ of the participants in the study by Arrey et al were between 20 and 29 years old. ${ }^{20}$ Older age is a strong determinant of hypertension. We noted a strong positive linear trend between older age and hypertension as has been observed in other studies in Cameroon 8122021 and elsewhere. ${ }^{22}$ Age-standardisation with Cameroon's population of 2011 permitted comparison of our results with those of Lemogoum et al. ${ }^{12}$ The age-standardised prevalence of hypertension in our study was half of the crude prevalence, indicating the contribution of age in the overall crude prevalence in this study. The

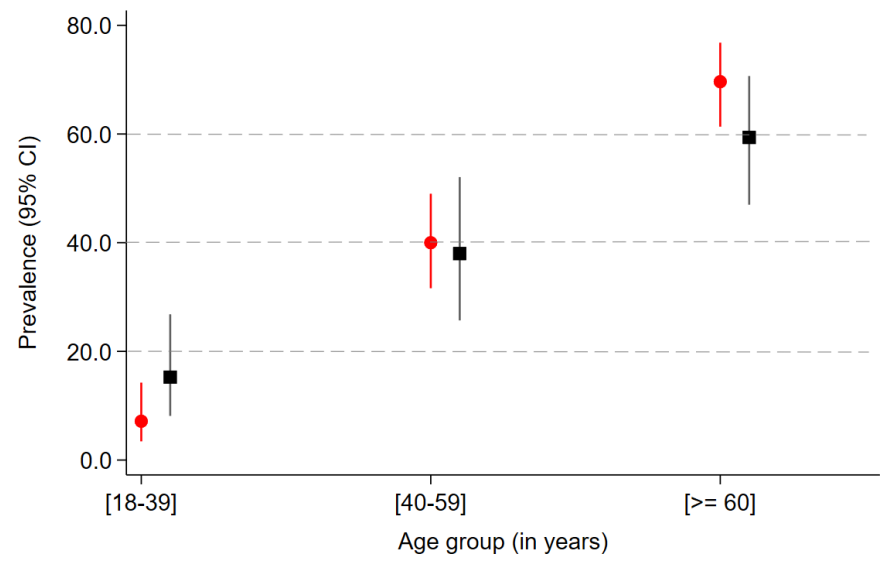

Figure 1 Prevalence (\%) (and 95\% Cl) of hypertension stratified by age and gender. The red circle and black square represent the point estimate of the prevalence of females and males, respectively. The spikes represent the limits of the $95 \% \mathrm{Cl}$. age-standardised prevalence in our study was lower than that reported by Lemogoum et al. ${ }^{12}$

Differences in ethnicity, socioeconomic and lifestyle factors could account for the variation in the prevalence of hypertension in our study compared with previous studies. ${ }^{812} 2021$ Our study recruited participants from the Bamileke ethnic group. In a recent publication by Kuate Defo et al, participants recruited from this ethnic group had the highest prevalence of hypertension in Cameroon. ${ }^{23}$ Our study suggests that genetic predisposition to hypertension is a significant determinant of hypertension in our study population as history of hypertension was associated with over twotimes increase in the odds of hypertension. Differences in BMI can explain, in part, the variation in the prevalence of hypertension in this study compared with other studies reporting on the prevalence of hypertension in rural Cameroon. ${ }^{12} 2021$ Over $60 \%$ of our study participants had a BMI over the normal range, and there was a strong positive linear relationship between hypertension and BMI. Adiposity is a strong risk factor for hypertension and an important driver of the prevalence of hypertension. ${ }^{24}$

In Cameroon, there has been a roll up in the prevalence of hypertension in the general population from $16.4 \%$ in $1998^{25}$ to $29.7 \%$ in $2015,{ }^{8}$ with recent projections estimating an increase of $40 \%$ by 2025 and $95 \%$ by $2035 .{ }^{26}$ The prevalence of hypertension in this study approximates prevalence of $47.5 \%$ and $41 \%$ reported in four urban areas in Cameroon in 2012, ${ }^{11}$ and a rural community in South Africa, ${ }^{27}$ respectively. Such high prevalence of hypertension, especially among the elderly, in these rural communities, warrants the need for further investigations to ascertain the burden of the disease and plan effective prevention and management strategies.

We found no independent association between hypertension and sex, education, marital status and physical activity, as has been reported in previous studies. ${ }^{120}$

\section{Awareness, treatment and control of hypertension}

We report a low awareness rate and even lower treatment and control rates among patients with hypertension in these communities. This is in line with findings reported in rural areas of the Far North and South West regions of Cameroon, ${ }^{120}$ and a meta-analysis by Ataklte et $a .^{28}$ In the Mafia Island of Tanzania, a low control rate of $20.5 \%$ was recorded despite the very high treatment rate. ${ }^{29}$ This is in contrast to the relatively higher control rates $(44.7 \%)$ reported in a rural community in Ghana. ${ }^{30}$

The low awareness, treatment and control rates reported in this study could be explained by inadequate patient information of the disease, its risk factors, and consequences in the long run. Low awareness is a major barrier to effective management which can lead to the development of hypertension-related complications. A paucity of healthcare professionals at the primary 
Table 2 Factors associated with hypertension in the Baham Health District on univariate analysis

\begin{tabular}{|c|c|c|c|c|}
\hline Participants' characteristics & $\begin{array}{l}\text { No hypertension } \\
(\mathrm{n}=311)\end{array}$ & $\begin{array}{l}\text { Hypertension } \\
(\mathrm{n}=215)\end{array}$ & $\begin{array}{l}\text { Total } \\
(n=526)\end{array}$ & $P$ value \\
\hline Age group (in years) & $42.0(28.0-58.0)$ & $64.0(53.0-73.0)$ & $53.0(35.0-65.0)$ & $<0.001^{\star}$ \\
\hline Gender & & & & $0.370 \dagger$ \\
\hline Female & 204 (65.6\%) & 149 (69.3\%) & 353 (67.1\%) & \\
\hline Male & $107(34.4 \%)$ & $66(30.7 \%)$ & $173(32.9 \%)$ & \\
\hline Marital status & & & & $<0.001 \dagger$ \\
\hline Married & $212(68.2 \%)$ & $191(88.8 \%)$ & $403(76.6 \%)$ & \\
\hline Single & $99(31.8 \%)$ & $24(11.2 \%)$ & $123(23.4 \%)$ & \\
\hline Occupation & & & & $0.017 \ddagger$ \\
\hline Low/unemployed & 218 (70.1\%) & $173(80.5 \%)$ & $391(74.3 \%)$ & \\
\hline Medium & $80(25.7 \%)$ & $33(15.3 \%)$ & $113(21.5 \%)$ & \\
\hline High & $13(4.2 \%)$ & $9(4.2 \%)$ & $22(4.2 \%)$ & \\
\hline Religion & & & & $0.180 \dagger$ \\
\hline Baptist & $11(3.5 \%)$ & $2(0.9 \%)$ & $13(2.5 \%)$ & \\
\hline Catholic & $154(49.5 \%)$ & $121(56.3 \%)$ & $275(52.3 \%)$ & \\
\hline Muslim & $11(3.5 \%)$ & $3(1.4 \%)$ & $14(2.7 \%)$ & \\
\hline Others & $74(23.8 \%)$ & 45 (20.9\%) & 119 (22.6\%) & \\
\hline None & $12(3.9 \%)$ & 7 (3.3\%) & 19 (3.6\%) & \\
\hline Presbyterian & $49(15.8 \%)$ & $37(17.2 \%)$ & $86(16.3 \%)$ & \\
\hline Level of education & & & & $<0.001 \ddagger$ \\
\hline None & $55(17.7 \%)$ & $76(35.3 \%)$ & $131(24.9 \%)$ & \\
\hline Primary & $81(26.0 \%)$ & $74(34.4 \%)$ & $155(29.5 \%)$ & \\
\hline Secondary & $130(41.8 \%)$ & $53(24.7 \%)$ & $183(34.8 \%)$ & \\
\hline Tertiary & $45(14.5 \%)$ & $12(5.6 \%)$ & $57(10.8 \%)$ & \\
\hline Family history of hypertension & & & & $0.002 \dagger$ \\
\hline No & $243(78.1 \%)$ & $142(66.0 \%)$ & $385(73.2 \%)$ & \\
\hline Yes & $68(21.9 \%)$ & $73(34.0 \%)$ & $141(26.8 \%)$ & \\
\hline Smoking status & & & & $0.760 \ddagger$ \\
\hline Non-smoker & $256(82.3 \%)$ & $179(83.3 \%)$ & $435(82.7 \%)$ & \\
\hline Ex-smoker & $28(9.0 \%)$ & $21(9.8 \%)$ & $49(9.3 \%)$ & \\
\hline Current smoker & $27(8.7 \%)$ & $15(7.0 \%)$ & $42(8.0 \%)$ & \\
\hline Exposure to wood smoke & & & & $0.048 \ddagger$ \\
\hline$\geq 4$ days/week & $200(64.3 \%)$ & $160(74.4 \%)$ & $360(68.4 \%)$ & \\
\hline$<4$ days/week & $75(24.1 \%)$ & $36(16.7 \%)$ & $111(21.1 \%)$ & \\
\hline Never & $36(11.6 \%)$ & $19(8.8 \%)$ & $55(10.5 \%)$ & \\
\hline Alcohol units per week & & & & $0.510 \ddagger$ \\
\hline Non-drinker & $92(29.6 \%)$ & $71(33.0 \%)$ & $163(31.0 \%)$ & \\
\hline$(0.012-6.49]$ & $120(38.6 \%)$ & 85 (39.5\%) & $205(39.0 \%)$ & \\
\hline (6.49 to 117] & $99(31.8 \%)$ & $59(27.4 \%)$ & $158(30.0 \%)$ & \\
\hline Daily consumption of vegetable per week & $1.0(1.0-2.0)$ & $1.0(1.0-2.0)$ & $1.0(1.0-2.0)$ & $0.230^{*}$ \\
\hline Daily consumption of fruit per week & $4.0(2.0-6.0)$ & $2.0(2.0-4.0)$ & $2.0(2.0-6.0)$ & $<0.001^{*}$ \\
\hline Intensity of daily physical activity & & & & $<0.001 \ddagger$ \\
\hline Low & $134(43.1 \%)$ & $134(62.3 \%)$ & $268(51.0 \%)$ & \\
\hline Moderate & 123 (39.5\%) & 72 (33.5\%) & 195 (37.1\%) & \\
\hline Vigorous & 54 (17.4\%) & $9(4.2 \%)$ & 63 (12.0\%) & \\
\hline
\end{tabular}

Continued 


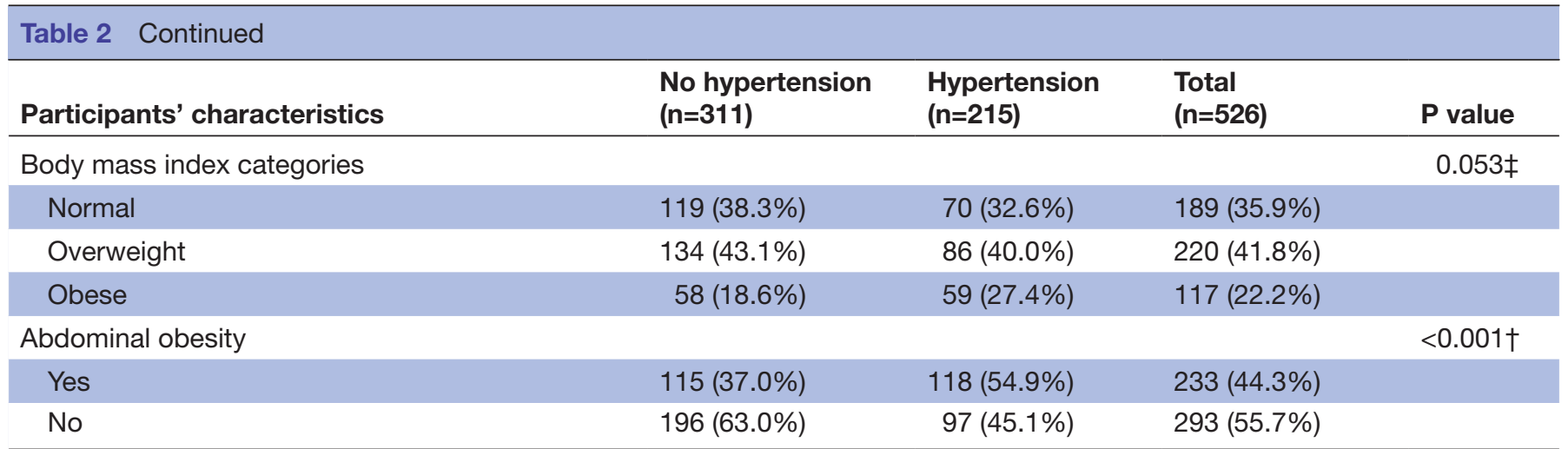

${ }^{*} P$ value from Wilcoxon rank sum test,

†P value from $\chi^{2}$ test for heterogeneity.

$\ddagger P$ value from $\chi^{2}$ test for trend

healthcare level and the absence of a hypertension clinic at the district hospital in our study setting limits awareness, treatment and control of hypertension in this population. Implementing policies to improve population education on hypertension and the importance of regular follow-up by a trained nurse or physician to prevent long-term complications would vastly improve awareness, treatment and control of hypertension in this setting. ${ }^{31}$ Other cost-effectiveness measures, including the use of home BP monitoring, could go a long way

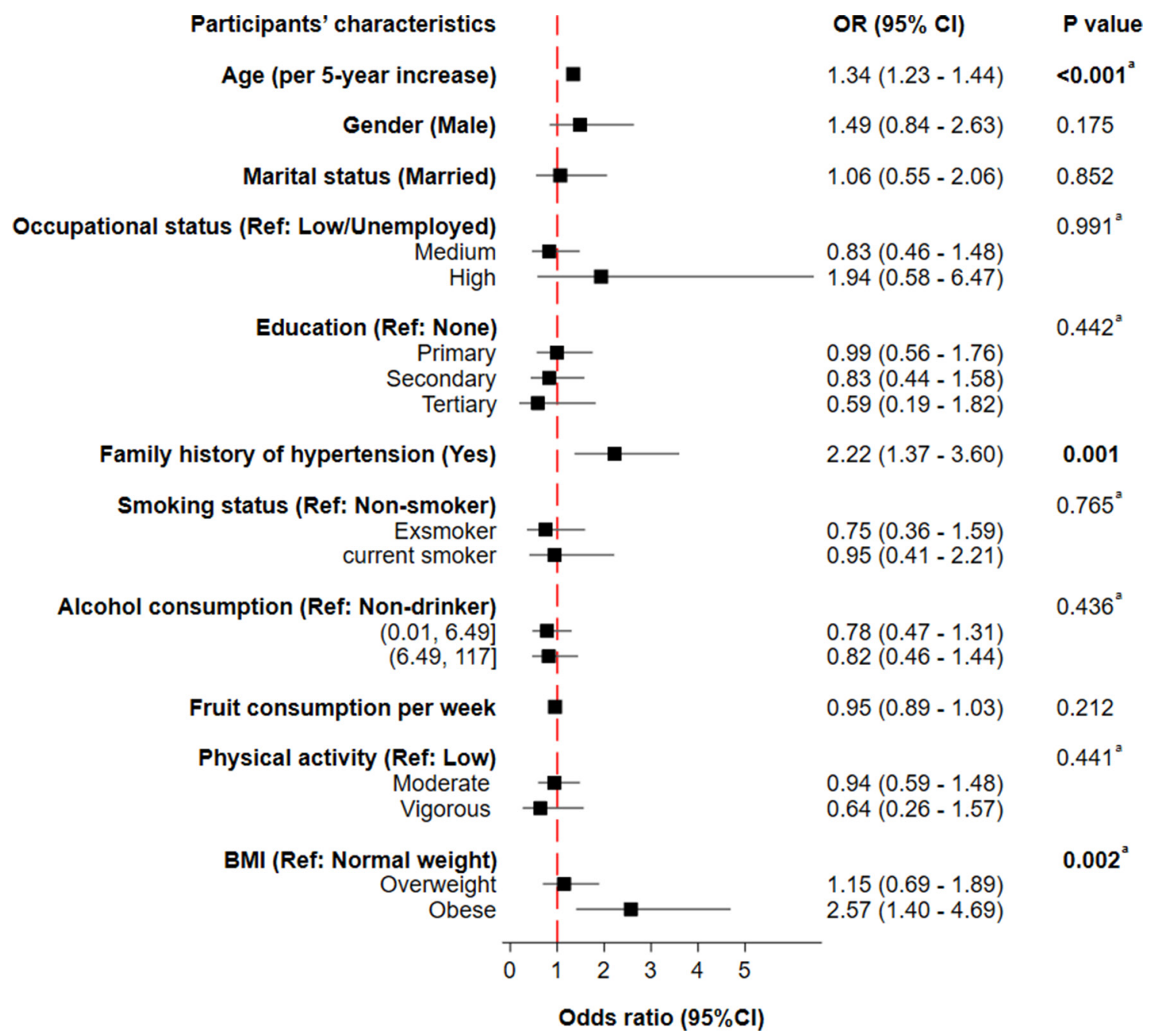

Figure 2 Factors associated with hypertension in the Baham Health District multivariable logistic regression analysis. Measures of associations are displayed as OR, black squares, with the $95 \% \mathrm{Cl}$, horizontal spikes. Significant p values are shown in bold. The red dashed line refers to the null value of 1.0. ${ }^{\mathrm{a}} \mathrm{P}$ value for trend. 
Table 3 Awareness, treatment and control of hypertension, Baham Health District, 2018

\begin{tabular}{lll}
\hline Outcomes & Frequency & $\begin{array}{l}\text { Percentage } \\
(\mathbf{9 5 \%} \text { Cl) }\end{array}$ \\
\hline $\begin{array}{l}\text { Hypertension } \\
\text { awareness }(n=215)\end{array}$ & 80 & $37.2(31.0-43.9)$ \\
$\begin{array}{l}\text { Hypertension treatment } 45 \\
(n=215)\end{array}$ & $20.9(16.0-26.9)$ \\
$\begin{array}{l}\text { Treated and controlled } \\
(n=45)\end{array}$ & 10 & $22.2(12.2-37.0)$ \\
\hline
\end{tabular}

$n$, frequency.

to improve adherence and control of hypertension in Cameroon. $^{32}$

\section{CONCLUSION}

About two in five participants in our study population had hypertension. The high prevalence of hypertension in this study was contrasted by low awareness, treatment and control rates. In a bit to curb the burden of hypertension in Cameroon, national policies need to adopt measures to address obesity and its risk factors. Measures to improve awareness of hypertension like regular community education, diagnosis, treatments and control could go a long way to reduce the burden of hypertension in this rural community.

\section{Twitter Valirie Ndip Agbor @ValirieAgbor}

Acknowledgements The authors are grateful for the invaluable contributions of all those who participated in the University of Bamenda Medical Student (UBaMSA) health campaign during the September 2018 edition. Also, we thank Ms Grace Heaton, a DPhil candidate in History at the University of Oxford, for proofreading our manuscript. Dr Agbor and Dr Noubiap are grateful to the University of Oxford and the University of Adelaide, respectively, for supporting them with postgraduate scholarships.

Contributors LPS, VNA and JJNN involved in study design and conception. LPS, OPN, PS-MN, AFAA, JNM, NFB and HGGT involved in data collection. VNA and LPS involved in data analysis and interpretation. LPS and VNA involved in manuscript drafting. LPS, OPN, PS-MN, AFAA, JJNN, JNM, NFB and HGGT involved in revision of the manuscript. VNA, JJNN and DM involved in critical revision of the manuscript. All authors read and approved the final manuscript.

Funding The authors have not declared a specific grant for this research from any funding agency in the public, commercial or not-for-profit sectors.

Competing interests None declared.

Patient consent for publication Not required.

Ethics approval Ethical approval was obtained from the Faculty of Health Sciences Institutional Review Board, the University of Bamenda (Project ID: 2018/0045 hour/ $\mathrm{UBa} / \mathrm{RB}$ ) and all participants provided written informed consent prior to recruitment to the study.

Provenance and peer review Not commissioned; externally peer reviewed.

Data availability statement Data are available upon reasonable request. All data presented in the manuscript results are in possession of the corresponding author and will be made available on reasonable demand.

Open access This is an open access article distributed in accordance with the Creative Commons Attribution Non Commercial (CC BY-NC 4.0) license, which permits others to distribute, remix, adapt, build upon this work non-commercially, and license their derivative works on different terms, provided the original work is properly cited, appropriate credit is given, any changes made indicated, and the use is non-commercial. See: http://creativecommons.org/licenses/by-nc/4.0/.

ORCID iD

Valirie Ndip Agbor http://orcid.org/0000-0002-6708-6852

\section{REFERENCES}

1 Kearney PM, Whelton M, Reynolds K, et al. Global burden of hypertension: analysis of worldwide data. Lancet 2005;365:217-23.

2 WHO. Global brief on hypertension. World Health Organization, 2013.

3 Lim SS, Vos T, Flaxman AD, et al. A comparative risk assessment of burden of disease and injury attributable to 67 risk factors and risk factor clusters in 21 regions, 1990-2010: a systematic analysis for the global burden of disease study 2010 . The Lancet 2012;380:2224-60.

4 Naghavi M, Abajobir AA, Abbafati C, et al. Global, regional, and national age-sex specific mortality for 264 causes of death, 19802016: a systematic analysis for the global burden of disease study 2016. The Lancet 2017;390:1151-210.

5 Noubiap JJ, Agbor VN, Ndoadoumgue AL, et al. Epidemiology of pericardial diseases in Africa: a systematic scoping review. Heart 2019;105:180-8.

6 Danwang C, Temgoua MN, Agbor VN, et al. Epidemiology of venous thromboembolism in Africa: a systematic review. J Thromb Haemost 2017;15:1770-81.

7 Adeloye D, Basquill C. Estimating the prevalence and awareness rates of hypertension in Africa: a systematic analysis. PLoS One 2014;9:e104300.

8 Kingue S, Ngoe CN, Menanga AP, et al. Prevalence and risk factors of hypertension in urban areas of Cameroon: a nationwide population-based cross-sectional study. J Clin Hypertens 2015;17:819-24.

9 Tianyi F, Agbor V, Njamnshi A. Prevalence, awareness, treatment, and control of hypertension in Cameroonians aged 50 years and older: a community-based study. health science reports, 2018.

10 Adidja NM, Agbor VN, Aminde JA, et al. Non-adherence to antihypertensive pharmacotherapy in Buea, Cameroon: a crosssectional community-based study. BMC Cardiovasc Disord 2018;18:150.

11 Dzudie A, Kengne AP, Muna WFT, et al. Prevalence, awareness, treatment and control of hypertension in a self-selected sub-Saharan African urban population: a cross-sectional study. BMJ Open 2012;2:e001217.

12 Lemogoum D, Van de Borne P, Lele CEB, et al. Prevalence, awareness, treatment, and control of hypertension among rural and urban dwellers of the far North region of Cameroon. $J$ Hypertens 2018;36:159-68.

13 Wikipedia. Baham, Cameroon Wikipedia, 2018. Available: https:// en.wikipedia.org/w/index.php?title=Baham,_Cameroon\&oldid= 866664358 [Accessed 14 Dec 2018]

14 Hernandez-Vila E. A review of the JNC 8 blood pressure guideline. Tex Heart Inst J 2015;42:226-8.

15 NHS. Alcohol units. Available: https://www.nhs.uk/live-well/alcoholsupport/calculating-alcohol-units/ [Accessed 14 Dec 2018].

16 WHO. What is moderate-intensity and Vigorous-intensity physical activity? Available: https://www.who.int/dietphysicalactivity/physical activity_intensity/en/ [Accessed 19 Dec 2018].

17 WHO. Body mass index.BMI, 2018. Available: http://www.euro.who. int/en/health-topics/disease-prevention/nutrition/a-healthy-lifestyle/ body-mass-index-bmi [Accessed 19 Dec 2018].

18 Okosun IS, Choi S, Dent MM, et al. Abdominal obesity defined as a larger than expected waist girth is associated with racial/ ethnic differences in risk of hypertension. J Hum Hypertens 2001;15:307-12.

19 Cameroon's National Institute of Statistics. Chapter 4: Characteristics of the population. In: Statistics year book 2010, 2011. http://www.statistics-cameroon.org/downloads/ annuaire2010/chap4.pdf

20 Arrey WT, Dimala CA, Atashili J, et al. Hypertension, an emerging problem in rural Cameroon: prevalence, risk factors, and control. Int J Hypertens 2016;2016:1-6.

21 Princewel F, Cumber SN, Kimbi JA, et al. Prevalence and risk factors associated with hypertension among adults in a rural setting: the case of Ombe, Cameroon. Pan Afr Med J 2019;34:147.

22 Wang J, Sun W, Wells GA, et al. Differences in prevalence of hypertension and associated risk factors in urban and rural residents 
of the northeastern region of the people's Republic of China: a crosssectional study. PLoS One 2018;13:e0195340.

23 Kuate Defo B, Mbanya JC, Kingue S, et al. Blood pressure and burden of hypertension in Cameroon, a microcosm of Africa. $J$ Hypertens 2019;37:2190-9.

24 Aronow WS. Association of obesity with hypertension. Ann Trans/ Med 2017;5:350.

25 Mbanya JC, Minkoulou EM, Salah JN, et al. The prevalence of hypertension in rural and urban Cameroon. Int J Epidemiol 1998;27:181-5.

26 Jingi AM, Dzudie A, Noubiap JJ, et al. PT075 trend in the prevalence, awareness, and control of hypertension in Cameroon: a systematic review and projections for 2025 and 2035. Glob Heart 2016;11:e138-9.

27 Ntuli ST, Maimela E, Alberts M, et al. Prevalence and associated risk factors of hypertension amongst adults in a rural community of Limpopo Province, South Africa. Afr J Prim Health Care Fam Med 2015;7:847.
28 Ataklte F, Erqou S, Kaptoge S, et al. Burden of undiagnosed hypertension in sub-Saharan Africa: a systematic review and metaanalysis. Hypertension 2015;65:291-8.

29 Muhamedhussein MS, Nagri ZI, Manji KP. Prevalence, risk factors, awareness, and treatment and control of hypertension in Mafia Island, Tanzania. Int J Hypertens 2016;2016:1-5.

30 Kweku M, Takramah W, Parby P, et al. Prevalence and awareness of hypertension among urban and rural traders in Hohoe Municipality, Ghana. Int J Sci Res 2017;4.

31 Dzudie A, Rayner B, Ojji D, et al. Roadmap to achieve 25\% hypertension control in Africa by 2025. Cardiovasc J Afr 2017;28:261-72.

32 Ndip Agbor V, Temgoua MN, Noubiap JJN. Scaling up the use of home blood pressure monitoring in the management of hypertension in low-income countries: a step towards curbing the burden of hypertension. J Clin Hypertens 2017;19:786-9. 